\title{
Compreensões de professores acerca do termo tarefa comunicativa
}

\author{
Marina Pereira Carandina \\ Instituto Federal de Educação, Ciência e Tecnologia de São Paulo \\ Campus São Carlos \\ mcarandina13@gmail.com \\ Rita de Cássia Barbirato \\ Universidade Federal de São Carlos \\ ritabarbi.m@gmail.com
}

\section{Resumo}

Temos por objetivo, neste artigo, apresentar e discutir resultados de uma investigação sobre como professores (formação inicial e continuada) compreendem o termo tarefa comunicativa após terem realizado um curso de extensão universitária sobre o planejamento baseado em tarefas (PBT). Procuramos também compreender em que medida esses professores, ao final do curso, são capazes de definir o conceito de tarefa e sua compreensão sobre os critérios que definem esse tipo de atividade. $\mathrm{O}$ curso de extensão foi ministrado em uma universidade federal do interior de São Paulo e abordou a teoria que embasa o conceito de tarefa comunicativa e sua elaboração (PRABHU, 1987; NUNAN, 1989; SKEHAN, 1996; ELLIS, 2003; XAVIER, 1999; BARBIRATO 2005). Como instrumentos de coleta de dados foram utilizados um questionário aplicado no início do curso, uma entrevista e a gravação da última aula do curso com a apresentação das tarefas elaboradas pelos alunos. Os resultados demonstram que o curso contribuiu muito para que os participantes compreendessem e pudessem definir o termo tarefa. Entretanto, reconhecemos serem necessários mais tempo e mais oportunidades de discussão, reflexão e utilização de tarefas na sala de aula para que a compreensão do termo tarefa possa ser mais profunda.

Palavras-chave: Tarefas comunicativas. Formação de professores. Ensino de línguas. 


\begin{abstract}
In this article, we aim to present and discuss the results of a research on how teachers define the term communicative task and its features after participating in a university extension course based on theorical principles of task-based approach (PRHABU, 1987; NUNAN,1989; SKEHAN, 1996; ELLIS, 2003; XAVIER, 1999; BARBIRATO, 2005). The extension course was taught at a federal university in the interior of Sao Paulo State. To collect data, we used a questionnaire, an interview, and recording of the last class of the course in which students presented their tasks. The results showed us that the course contributed greatly to the participants' understanding of the term "task" once they could define it. However, we recognize that more time and opportunities for discussion, reflection, and implementation of tasks in the classroom, besides its elaboration, were needed to understand the concept more deeply.
\end{abstract}

Keywords: Communicative tasks. Pre-service teacher education. Language teaching.

\title{
1 Introdução
}

Temos por objetivo, neste artigo, apresentar e discutir resultados acerca de uma investigação que buscou melhor compreender como professores (formação inicial e continuada) entendem o Planejamento Baseado em Tarefas (PBT), mais precisamente o termo tarefa, após terem realizado um curso de extensão universitária sobre o referido tipo de planejamento. Buscamos compreender até que extensão os professores, ao final do curso, são capazes de definir o conceito de tarefa, conceito-chave para esse tipo de planejamento, e em que extensão eles apresentaram compreensão sobre os critérios que definem esse tipo de atividade.

Estudos anteriores (ELLIS, 2003; XAVIER, 1999, 2016; BARBIRATO, 2005, 2016; CARANDINA, 2015, 2017; BARBIRATO; CARANDINA, 2018, entre outros) têm demonstrado que nem sempre a compreensão do termo tarefa é clara o suficiente para professores de línguas. Tal incompreensão, muitas vezes, pode levar o professor a criar crenças equivocadas, como, por exemplo, de que toda atividade seja tarefa ou que seja tarefa de casa, entre outros (BARBIRATO, 2005; XAVIER, 1999). Para que o professor seja capaz de utilizar tarefas em sala de aula, e até mesmo elaborá-las, defendemos a necessidade de que ele tenha uma compreensão clara dos princípios que fundamentam tal conceito. 
Reconhecemos o papel do professor como fundamental para o desenvolvimento do aluno no processo de ensino e aprendizagem de línguas, por isso consideramos a necessidade de, durante seu processo de formação, tanto inicial quanto continuada, ele ser exposto a diferentes teorias de ensino e aprendizagem, pois essas oportunidades de experiência e reflexão com diferentes tipos de planejamentos e teorias podem contribuir muito para o amadurecimento e o desenvolvimento profissional do professor, bem como para sua atuação em sala de aula (VIEIRA ABRAHÃO, 2006).

Além disso, defendemos que o estudo sobre o Planejamento Baseado em Tarefas (PBT) pode ser uma experiência relevante para os professores em formação porque se trata de um tipo de planejamento alinhado com um ensino voltado para a comunicação de forma contextualizada e significativa. Tais conceitos, de acordo com autores da área (ELLIS, 2003; SKEHAN, 1996; XAVIER, 1999, BARBIRATO, 2005), podem contribuir para que a aquisição de língua estrangeira ocorra na sala de aula. Por fim, várias pesquisas têm sido realizadas sobre esse tipo de planejamento com resultados positivos, porém são necessários mais estudos sobre o tema (XAVIER, 1999; BARBIRATO, 2005; CASSOLI, 2011; FRANCISCHINE, 2013; EMÍDIO, 2017; PÉRICO, 2018).

Reconhecemos que os cursos de formação inicial e continuada são contextos que podem proporcionar ao professor experiências de conhecimento de teoria e prática que permitem ao (futuro) profissional refletir sobre aquilo que faz, com o intuito de gerar compreensões mais aprofundadas sobre conceitos como: língua, linguagem, língua estrangeira (LE) e ensinar e aprender LE (ALMEIDA FILHO, 1993). Destacamos, nesse contexto, os cursos de extensão universitária como um rico espaço para a promoção da prática reflexiva. Por isso optamos por realizar um curso apresentando os princípios norteadores do PBT, de modo que os professores participantes fossem levados a refletir sobre o ensino baseado em tarefas e, posteriormente, a analisar os resultados de tal experiência. Para tanto, a seguinte pergunta de pesquisa norteou nossa investigação: após ter participado de um curso de extensão sobre o planejamento baseado em tarefas, como os professores participantes podem definir o conceito de tarefa? 
Com base nessa questão de pesquisa, apresentamos, na sequência, a fundamentação teórica que sustenta o referido planejamento e que também embasou o curso de extensão realizado para os participantes.

\section{Fundamentação teórica}

Quando tratamos do processo de aquisição de uma língua estrangeira na sala de aula, os tipos de experiências nas quais os aprendizes se engajam (PRABHU, 1987; ELLIS, 1994; KUMARAVADIVELU, 1994) devem ser levados em conta, pois elas podem maximizar as oportunidades de aprendizagem para os alunos e oferecer um caminho mais efetivo para se alcançar a competência comunicativa na língua-alvo.

Pensando nesses tipos de experiências criados em sala de aula, temos o Planejamento Baseado em Tarefas (PTB), o qual está centrado no processo (PRABHU, 1987) e é organizado em torno de uma sequência de tarefas.

Defendemos o PBT como um planejamento que pode promover o desenvolvimento das quatro habilidades da língua (compreensão oral, escrita, produção oral e escrita), pois ele apresenta uma visão de linguagem voltada para a comunicação, e, devido a isso, o aluno terá oportunidades de utilizar a língua em situações semelhantes às do cotidiano. Além disso, a comunicação é promovida a fim de se adquirir a língua-alvo por meio de um ambiente interativo, significativo e relevante para o aprendiz. Assim posto, a tarefa passa a ter um lugar de destaque e assume um papel importante no processo de ensino e aprendizagem na sala de aula.

A tarefa é entendida, neste trabalho, como uma atividade que exige o uso da língua com foco no significado para se chegar a um resultado (SKEHAN, 2003). Diante disso, compreendemos a tarefa como um construto que vai além de um instrumento para comunicação, ou seja, tratase de uma unidade de ação na língua-alvo que pode promover, por meio de interações significativas, a negociação, a construção, a desconstrução e a reconstrução de sentidos, contribuindo, dessa forma, para a aquisição da língua-alvo.

Da mesma maneira, para Nunan (1989, p. 10), a tarefa é uma atividade que tem o objetivo de "envolver o aluno na compreensão, 
manipulação, produção ou interação na língua-alvo" com foco voltado para a construção de significado e não para a forma. Concordando com o autor, Barbirato $(2005$, p. 3$)$ define tarefa como "uma parte do trabalho de sala de aula responsável por criar um ambiente para se adquirir LE". Esse ambiente, para a autora, é gerado para se "viver comunicação" entre os indivíduos quando esses "interagem e negociam significados", enquanto o foco mantém-se sempre no sentido. Esse é, também, um dos critérios que define tarefa para Skehan (1996), pois, para ele, o termo pode ser definido como uma atividade que requer o uso da língua com foco no significado para se atingir um objetivo.

A tarefa diferencia-se de outros tipos de atividades, visto que apresenta critérios definidores que a constituem. Assim, para entender o que é tarefa, e até para elaborá-la, consideramos necessário conhecer os critérios que a definem. Diante disso, os critérios definidores de tarefa selecionados por nós, nesta pesquisa, são:

- Foco no sentido (PRAHBU, 1987; NUNAN, 1989, SKEHAN,1996; WILLIS,1996; XAVIER,1999; ELLIS, 2003; BARBIRATO; 2005, 2016);

- Resultado (SKEHAN, 1996; XAVIER, 1999, 2016; ELLIS, 2003; BARBIRATO; 2005, RICHARS, 2006).

- Potencial para promover interação na língua-alvo (XAVIER, 1999; BARBIRATO; 2005);

- Uso da língua-alvo em situações semelhantes às vivenciadas pelos alunos fora da sala de aula (SKEHAN, 1996; ELLIS, 2003; BARBIRATO; 2005);

- Natureza significativa e relevante das tarefas (BARBIRATO, 2005);

- Eixo organizatório temático (assunto de outras disciplinas, conteúdos de filmes, textos com temas interessantes, entre outros) (BARBIRATO, 2005; XAVIER, 1999).

Reconhecemos que alguns dos critérios elencados por nós como definidores do termo tarefa não são exclusivos desse tipo de atividade, uma vez que podem abranger outros tipos de atividades e incluir aspectos como: trabalho com temas, uso da língua em contextos semelhantes aos do mundo real, processos cognitivos e práticas que promovam interação. 
Para Ellis (2003), os critérios foco no sentido e resultado comunicativo são os que diferenciam majoritariamente tarefas de exercícios. Além disso, para o autor, o que irá determinar cada tipo de atividade é o foco, seja ele no significado (tarefas) ou na forma (exercícios). Nesse caso, a diferença somente poderá ser percebida se o objetivo do elaborador da tarefa ou do exercício for identificado (XAVIER, 2007). No caso das atividades, elas compreendem um termo mais amplo, como estabelecido por Almeida Filho e Barbirato (2000, p. 29), porque, segundo os autores, "atividade é, pois, o termo genérico para ações realizadas na sala que são reconhecidas como orgânicas e semelhantes às atividades que os alunos encontram fora da sala de aula". Assim, toda tarefa é considerada uma atividade, mas nem toda atividade pode ser classificada como tarefa, pelo fato de a tarefa ser mais específica que a atividade.

Reconhecemos, então, que o professor pode enfrentar dificuldades para implementar tarefas em sala de aula (ELLIS, 201) e classificar uma atividade como tarefa ou exercício (XAVIER, 2007). Há, ainda, uma dificuldade dos professores em materializar os princípios que as norteiam, na maioria das vezes devido a uma forte cultura de ensinar calcada na visão tradicionalista, ou seja, voltada para a forma (CARANDINA, 2015). Pudemos verificar em nossa pesquisa bibliográfica um número reduzido de pesquisas em contexto nacional com foco no professor utilizando esse tipo de planejamento em sala de aula.

No planejamento baseado em tarefas, as definições apresentadas sobre o papel do professor centram-se na concepção do professor como colaborador na aprendizagem do aluno. Xavier (1999, p. 41) define o papel do professor como o "de negociador, orientador, integrador de grupos, questionador, facilitador e avaliador”. Com definição semelhante à da autora, Barbirato (2005, p. 112) argumenta:

O papel do professor dentro desta proposta passa a ser redimensionado. Ele passa a ser uma importante fonte de insumo para o aluno e também um gerenciador da realização das tarefas ajudando-os a iniciar perguntas e comentários, por exemplo, e a entender o que é esperado deles e como eles devem conduzir sua aprendizagem. O professor tem também o papel de avaliar a 
realização das tarefas e de atender as necessidades dos alunos durante o processo (BARBIRATO 2005, p. 112).

O uso de tarefas em sala de aula mostra-se diferente do ensino tradicional em questões de metodologia e objetivos. Por isso, quando o ensino baseado em tarefas é apresentado como uma opção, o professor pode se sentir inseguro quanto aos conhecimentos e às habilidades comunicativas envolvidos e que ele julgue não possuir (XAVIER, 2011). Segundo Xavier (2011, p. 167), "o medo de inovar não pode dominar o profissional, que deve estar sempre em busca de sua melhor capacitação e atuação como educador". Concordamos com a autora e defendemos que a atuação dos professores com tarefas, no estudo sobre seus princípios teóricos, na elaboração e na implementação das tarefas, constitui uma oportunidade que pode trazer benefícios para sua formação, seja ela inicial ou continuada.

Além disso, Xavier (2007, p. 14) defende que os princípios embasadores do uso de tarefas na aula de línguas deveriam ser apresentados e discutidos nos cursos de formação inicial de professores, bem como nos programas de formação continuada, com o intuito de oferecer ao professor conhecimentos teóricos e oportunidades de prática para que ele possa "analisar, avaliar, selecionar, adaptar e produzir seus próprios exercícios e tarefas". Ainda de acordo com a autora:

O processo de elaboração, implementação e avaliação de tarefas ou exercícios, permite que os professores reflitam antes, durante e depois sobre ações relacionadas a: objetivos, conteúdo, formato, sequência, procedimentos, correção, atividades boas e ruins, resultados de aprendizagem, atitudes de professores e alunos. Essa forma de conscientização deriva do processo de tomada de decisão dos professores, que, por sua vez, é resultado de suas teorias e crenças implícitas, conhecimento e habilidades adquiridos (XAVIER 2007, p. 14) (tradução nossa). ${ }^{1}$

\footnotetext{
${ }^{1}$ The process of task / exercise design, implementation, and assessment enables the teachers to reflect before, during and after their actions on goals, content, format, sequence, procedures, correction, good/ bad activities, learning results, teachers' and students' attitudes. This form of teaching 15 awareness evolves from the
} 
É nesse sentido, reiterado pela autora, que este estudo se alinha e busca aprofundar compreensões sobre como professores, tanto em formação inicial quanto continuada, após terem participado de um curso sobre o PBT, conseguem compreender e explicar o termo tarefa. Acreditamos que este estudo e conhecimento sobre o PBT pode contribuir para a reflexão de professores a respeito da construção de um ensino mais significativo e relevante para alunos na sala de aula, com maior potencial para que a aquisição ocorra, podendo contribuir não só para o processo de formação de professores, mas também para os processos de ensinar e aprender línguas na sala de aula.

\section{Metodologia da investigação}

Este estudo insere-se na abordagem qualitativa de base interpretativista e foi realizado em uma universidade federal de uma cidade do Estado de São Paulo com professores em processo de formação inicial e continuada com base em um curso ofertado pelas autoras deste artigo sobre a elaboração de atividades comunicativas com foco em tarefas. O intuito de ofertar o curso surgiu com os resultados de pesquisas anteriores (CARANDINA, 2015, 2017) a respeito do ensino baseado em tarefas e a formação de professores, cujos resultados demonstraram os desafios enfrentados pelos professores com relação ao ensino sobre tarefas e apontaram para a falta de conhecimento teórico como possível fonte da dificuldade de compreensão e definição do termo e, principalmente, da elaboração das tarefas.

Foi, então, elaborado o referido curso de extensão universitária, com vinte vagas. A divulgação foi realizada via redes sociais da universidade na qual o curso foi oferecido. $\mathrm{O}$ público-alvo foram professores de línguas de formação inicial e continuada. As primeiras vinte inscrições que chegassem ao e-mail divulgado preencheriam as vagas do curso. Tivemos 17 inscritos, porém apenas sete frequentaram 75\% (ou mais) das aulas e tornaram-se nossos participantes de pesquisa.

teachers' decision making process that, in its turn, results from their implicit theories and beliefs, experiential knowledge and skills (XAVIER 2007, p. 14). 
Tomando por base um questionário respondido no momento da inscrição foi possível delinear algumas características dos participantes. Desse modo, constatamos:

- Com exceção de uma participante, todos os outros participantes estavam matriculados na universidade na qual o curso de extensão foi oferecido, alguns na graduação em Letras, outros no programa de pós-graduação em estudos linguísticos.

- $\quad$ Quatro participantes eram professores em formação inicial (encontravam-se no primeiro ano da graduação no momento da coleta de dados).

- Três participantes eram professores em formação continuada (graduados no curso de Letras).

- Três dos participantes seriam habilitados a ministrar aulas de Língua Inglesa ao final da graduação.

- Uma participante era habilitada a ministrar aulas em Língua Inglesa.

- Um dos participantes seria habilitado a ministrar aulas de Língua Espanhola ao final da graduação.

- Dois participantes eram habilitados a ministrar aulas de Língua Espanhola.

- Dois participantes estavam cursando pós-graduação: um no mestrado e outro no doutorado.

A fim de preservar a identidade dos participantes, para cada um foi designado um pseudônimo, sendo: Vivian e Eduardo, professores em formação inicial (FI), e Aline, Carla, Gabriela, Jorge e Manuela, todos professores em formação continuada (FC).

\subsection{O curso de extensão sobre o Planejamento Baseado em Tarefas}

O curso foi composto por sete encontros realizados toda quintafeira, das $9 \mathrm{~h}$ às $11 \mathrm{~h}$, completando uma carga horária de 14 horas/aula. O curso foi ministrado pelas autoras deste artigo. Os encontros foram organizados da seguinte maneira: 
19 encontro - os alunos e as professoras tiveram a oportunidade de se conhecer e também foram apresentados ao que viria a ser realizado no decorrer do curso, assim como às teorias a serem estudadas, referentes aos trabalhos de Almeida Filho (1993), Barbirato (1999, 2005), Xavier (1999), entre outros. Nesse encontro também foi perguntado aos alunos se eles gostariam de participar desta pesquisa, e todos concordaram. Foi, então, solicitado que eles assinassem o termo de consentimento livre esclarecido (Apêndice A). Em seguida, eles responderam ao primeiro questionário para a coleta de dados.

20 encontro - ao final da primeira aula foi pedida aos alunos a leitura do texto Ambientes comunicativos para aprender Língua Estrangeira (ALMEIDA FILHO; BARBIRATO, 2000), que tinha como temática principal o uso de atividades comunicativas. Nesse encontro foi realizada a discussão do referido texto. Os alunos foram divididos em pequenos grupos, e cada grupo ficou responsável por discutir uma parte do texto e, na sequência, apresentar para a classe a discussão realizada.

3o encontro - a discussão da última aula foi retomada. Foram também apresentados novos aspectos de teorias referentes ao Planejamento Baseado em Tarefas, assim como o uso e a elaboração de tarefas para aulas de LE. Os conceitos apresentados e discutidos foram: conceitos de língua; linguagem; conceito de ensinar língua estrangeira; conceito de aprender língua estrangeira, baseados nos pressupostos teóricos abordados por Almeida Filho (1993) em seu livro Dimensões comunicativas no ensino de línguas; princípios do PBT; e definição de tarefas (PRABHU, 1987; SKEHAN, 1996; ELLIS, 2003).

4⿻ encontro - nos primeiros trinta minutos da aula foi realizada uma discussão baseada nos pressupostos teóricos apresentados no encontro anterior sobre os princípios que sustentam o PBT e sobre o conceito de tarefas com perguntas para os alunos quanto às suas dúvidas e posições a respeito do assunto. A partir desse encontro o número de participantes começou a diminuir. Não tivemos a oportunidade de apurar os motivos das desistências.

5o encontro - durante o quinto encontro continuamos com as discussões sobre os critérios definidores de tarefa, como reconhecer uma tarefa, aspectos que diferenciam tarefas de exercícios. Alguns exemplos de tarefas retirados de autores como Nunan (1989) e Prabhu (1987) foram 
entregues para que os alunos analisassem e discutissem na aula. Nessa aula também foi solicitado aos alunos que começassem a se preparar para a elaboração das atividades que deveriam ser apresentadas ao final do curso.

$6^{\mathbf{0}}$ encontro - o sexto encontro foi destinado à discussão das tarefas exemplos, as quais foram entregues para os alunos na aula anterior. Ao final da aula foi informado aos alunos que para o próximo e último encontro eles deveriam elaborar as próprias atividades (de três a cinco) baseadas no que havia sido estudado até o momento. A pesquisadora mostrou-se disponível para auxiliá-los nesse processo caso fosse necessário. A última aula para apresentação das tarefas elaboradas ficou marcada para 15 dias após a penúltima aula a fim de que os alunos tivessem um tempo maior para elaborar as tarefas.

7ํㅜ encontro - no último encontro os alunos apresentaram as atividades por eles elaboradas. A cada apresentação era proposta uma discussão entre todos os alunos a respeito das atividades apresentadas, dos conceitos de tarefas e das teorias estudadas ao longo do curso. Após o encerramento do curso os alunos foram convidados a responder a uma entrevista, tendo recebido um certificado de conclusão do curso.

Como instrumentos de coleta de dados foram utilizados três instrumentos: a) questionário no início do curso, b) entrevista com os alunos ao final do curso e c) gravação da última aula do curso com a apresentação das tarefas elaboradas pelos alunos. $O$ questionário foi analisado, tabulado e usado para triangular dados na análise. A gravação da última aula foi transcrita na íntegra, e as partes consideradas importantes foram trazidas para a análise. Determinamos chamar de relatos as partes transcritas da última aula, nas quais os alunos explicam as tarefas que elaboraram. Os dados foram categorizados de acordo com os critérios apresentados no curso e apontados na fundamentação teórica deste artigo como definidores do termo tarefa. Após a categorização, os dados foram triangulados e analisados. 


\section{Análise dos dados}

\subsection{Compreensões dos professores em formação (FC e FI) sobre o conceito de tarefa comunicativa}

Com o intuito de melhor compreender até que medida professores em formação podem definir o termo tarefa comunicativa ao término de um curso de extensão sobre o PBT, apresentamos e discutimos os dados gerados e coletados neste estudo com o objetivo de responder à nossa pergunta de pesquisa. Uma das perguntas da entrevista, realizada com os participantes, pedia que estes definissem o termo tarefa. A seguir, apresentamos as respostas dos participantes para essa pergunta, começando por Aline:

\section{Excerto 1. Aline}

Eu acho que eu explicaria (.) é quando você monta um (.) é um :: (.) você tem uma abordagem né? De ensino (.) de que você vai se focar mais na interação dos alunos (.) com o foco no sentido (.) a gente não tem mais essa preocupação com item gramatical (.) de fórmulas (.) de você tentar ensinar eles (.) pra que decorem algo (.) mas que você foque mais no sentido (.) dessa interação de todos os alunos (.) pra que eles consigam (.) e praticar (.) não praticar a língua né? (.) e utilizar a língua sem que seja por regrinhas ou decoração (.) decorar algo. (Entrevista) (CARANDINA, 2019 p. 116)

Para Aline, a tarefa envolve, primeiramente, uma abordagem, visão essa coerente, uma vez que o Planejamento Baseado em Tarefas é uma das materializações da abordagem comunicativa. Esta tem como concepção a língua para comunicação, ou seja, quando a participante menciona que no PBT o intuito é envolver os alunos no uso da língua em vez da memorização de regras, notamos que ela compreendeu a teoria apresentada no curso. No PBT, a visão de linguagem é voltada para a comunicação a fim de que o aluno possa, por meio de um ambiente com interação significativa e de relevância para o aluno, adquirir a língua-alvo (BARBIRATO, 2005). A interação é mencionada por Aline como um definidor do Planejamento Baseado em Tarefas, assim como o foco no sentido, um dos critérios definidores de tarefa apontado por vários autores 
(SKEHAN, 1996; ELLIS, 2006; RICHARDS, 2006; NUNAN, 1989; XAVIER, 1999; BARBIRATO, 2005).

Jorge (FC) também concebe o PBT como um ensino que privilegia a interação, como é possível perceber pelo trecho a seguir:

\section{Excerto 2. Jorge}

Eu entendi que é uma coisa que não é feita individualmente (.) ela é feita coletivamente (.) é um aprendizado que não é um aprendizado é :: autodidata (.) você precisa ter uma interação. (Entrevista) (CARANDINA, 2019 p. 117)

Um ponto destacado por Jorge é o fato de a atividade não ser realizada individualmente, e sim coletivamente, perspectiva que concorda com a definição de Barbirato (2005). Esta autora defende que a interação tem por fundamento a colaboração para se chegar a propósitos comunicativos. Para ela, outros aspectos que definem as tarefas são a natureza significativa e relevante da tarefa e a semelhança com situações que os alunos encontram fora de sala de aula. Corroborando essas definições, Manuela (FC) argumenta que as tarefas são atividades que se inserem em um contexto de interesse do aluno, ou seja, algo que lhe seja familiar, fazendo com que ele se identifique, como mostra o relato durante a última aula do curso de extensão:

\section{Excerto 3. Manuela}

Eu acho que sim (.) ainda mais com o que eu venho lendo a tarefa ela tá muito ligada com o atual do aluno (.) eu acho que essa temática é um pouco mais atual (.) um pouco mais próxima pro aluno (.) então ela acaba se identificando e motivando ele a continuar (.) a fazer o curso (.) a realizar a tarefa e tudo mais (Relato durante o curso de extensão) (CARANDINA, 2019 p. 117)

Manuela (FI) destaca dois pontos importantes para a definição do PBT. Primeiro, o aluno identificar-se com o tema utilizado na tarefa e, segundo, sentir-se motivado pelo tema proposto. Ela destaca, dessa forma, dois critérios definidores de tarefa, ou seja: i) ser semelhante com o que o aluno vivencia fora da sala de aula e ii) ser interessante e significativa para o aluno. 
De acordo com Van den Branden (2009), o professor assume, juntamente com as tarefas, o papel de motivador, afinal ele pode perceber o que pode ser de interesse ou não para os alunos, além de propor temas que irão motivá-los para realizar a tarefa. Além disso, elaborar as tarefas com base em temas relevantes e significativos para os alunos é um dos critérios definidores de tarefa proposto por Barbirato (2005). Manuela (FI) também reconhece que as tarefas não são somente atividades que privilegiam a habilidade oral, mas também podem possibilitar o trabalho com outras habilidades, conforme podemos observar no excerto a seguir:

\section{Excerto 4. Manuela}

Eu vejo assim que é aquele : : (.) é uma atividade que tá inserida no contexto familiar / não familiar/ familiar pro aluno (.) e que ele precisa não só treinar a habilidade dele na língua (.) mas também né?(.) aquela parte da leitura (.) da compreensão (.) da comunicação entre os outros colegas (.) treina muito essa parte da comunicação mesmo (Entrevista) (CARANDINA, 2019 p. 118)

As afirmações de Manuela (FI), no excerto anterior, convergem com os argumentos de Ellis (2006), quando o autor defende que o PBT pode promover o desenvolvimento das quatro habilidades linguísticas (compreensão oral e escrita, produção oral e escrita) e também oportunidades para que os alunos possam atuar em contextos de uso da língua-alvo fora da sala de aula, como Manuela mencionou.

Eduardo (FI) também apresentou como concepção sobre o PBT um ensino que privilegie temas que promovam a interação e que o foco esteja no significado, como podemos perceber nos trechos a seguir, retirados da entrevista e de uma discussão realizada no decorrer do curso:

Excerto 5. Eduardo

eu acho que é muito importante pra (.) pra questão de interação (.) de contato com a língua (.) e até mesmo pra evitar a dispersão do aluno quando você tem um tema por trás (Entrevista)

\section{PROFESSORA}

Qual é o primeiro critério que você olha e fala assim (.) ah (.) é tarefa? Então o que vocês pensaram? 
Eduardo

eu (.) primeiro eu olhava se (.) o foco era no sentido (Relato durante o curso de extensão) (CARANDINA, 2019 p. 118)

Eduardo (FI) menciona que a interação é um ponto muito importante do PBT, pois ela promove o contato com a língua, enquanto o tema pode auxiliar na motivação do aluno, ponto também defendido por Manuela, como vimos anteriormente. Outro dado merecedor de atenção é o fato de o professor ter compreendido que o foco no sentido é um dos critérios definidores de uma tarefa, diferentemente de um exercício, em que o foco está na gramática ou na prática de itens linguísticos. Os critérios mencionados por Eduardo corroboram a visão de autores como Skehan (1996), de que as tarefas são atividades nas quais o foco está no sentido, representam situações do mundo real e propõem uma conclusão, um resultado.

Gabriela (FC) também concebe as tarefas como atividades com um propósito, um resultado a ser alcançado e com potencial para promover interação, como podemos perceber, a seguir, nos trechos retirados da entrevista e do relato durante a última aula do curso de extensão:

\section{Excerto 6. Gabriela}

é uma atividade que envolve um processo de aquisição e aprendizagem de língua (.) que tem um propósito né? (.) um fim em si (.) um resultado (.) mas que vai exigir a comunicação e interação

(...)

ai eu penso também que a tarefa pode envolver um aprendizado de gramática (.) mas é um (.) um trabalho que o aluno / um trabalho entre aspas que ele desenvolve (.) e que tem o propósito de se comunicar e de interagir (.) principalmente (.) acho que a tarefa ficou bem claro pra mim por isso (.) o propósito de comunicação e interação né? (Entrevista)

\section{PROFESSORA}

Você considera essa atividade uma tarefa?

GABRIELA

Eu penso que sim! (.) eu tava pensando (...) porque ela tem um proposito (.) ela tem uma proposta comunicativa (.) e ela leva a 
interação (.) (Relatos durante o curso de extensão) (CARANDINA, 2019 p. 119)

Quando Gabriela (FC) diz que a tarefa tem um propósito em si, observamos que ela se refere a um dos critérios definidores de tarefa: o resultado. De acordo com Barbirato (2005), atingir um resultado é um dos critérios que muitos autores (SKEHAN, 1996; RICHARDS, 2006; ELLIS, 2003; XAVIER, 1999) parecem concordar ao definir tarefas. De maneira geral, concluímos que as definições de Gabriela sobre tarefas se assemelham a alguns critérios definidores presentes na literatura da área, como: tarefas são atividades que privilegiam a comunicação, podem promover interação e devem ter uma finalidade, ou seja, um resultado.

Gabriela mencionou na entrevista, como apresentamos a seguir, a preocupação, como aluna, de aprender uma língua com um professor falante nativo, além de também acreditar na importância de se aprender os aspectos gramaticais da língua-alvo. Em relação às tarefas, ela acredita que, caso sejam utilizadas para aprendizagem de itens linguísticos, de maneira semelhante ao ensino de cunho tradicional, a tarefa pode falhar, como podemos perceber pelo trecho a seguir:

\section{Excerto 7. Gabriela}

mas eu acho que :: se a gente for seguir aquela perspectiva de que :: do mito do / considerando o mito do falante nativo (.) você usar a língua do jeitinho que ela vai ser usada / tipo tem que ser naquela estrutura (.) a tarefa vai falhar (.) agora se eu deixo o aluno / por exemplo pra falante de outras línguas básico de PLE (.) gente vocês vão / por exemplo fazer um (.) fazer um cartaz de uma propaganda combatendo o câncer de mama (.) usem o máximo de português possível (.) tudo bem se usar um pouco de inglês (.) então AÍ SIM ela pode acontecer (.) ai sim (.) se não ela vai falhar (.) a gente tem que conscientizar o aluno /preocupem-se em fazer a atividade e não em falar o português correto (.) se não vai criando aquele receio né? (.) se não cai na gramática de novo (Entrevista) (CARANDINA, 2019 p. 120)

Observamos, também, um aspecto importante apontado por Gabriela (FC) sobre o uso de tarefas em sala de aula: o fato de a professora ter percebido que o PBT não se resume em fazer com que o aluno consiga 
aprender a língua padrão ou então falar de acordo com as regras, mas sim o desenvolvimento processual da linguagem para que se possa, por meio de um ambiente interativo, adquirir a língua-alvo (BARBIRATO, 2005). A abordagem dos professores é, muitas vezes, marcada por sua Competência Implícita, principalmente os professores que se encontram em um estágio inicial de sua formação (ALMEIDA FILHO, 1993). Dessa forma, defendemos que os professores que possivelmente passaram por um ensino calcado no estruturalismo possam questionar a eficácia de um planejamento cujo foco não seja a forma. Esse é o caso de Eduardo (FI), demonstrado no trecho a seguir:

\begin{abstract}
Excerto 8. Eduardo
Eu acho que o ensino sobre tarefas (.) ele ainda precisa ser muito estudado sabe? (.) embora tenha muito conteúdo teórico (.) muita gente tem dúvida sobre a eficiência dele (.) e eu tenho algumas dúvidas sobre a eficiência dele se utilizar ele (.) como um todo assim (.) pensando no aluno sabe? E o aluno que começa sem saber nada do início ao fim será que ele (.) será que esse ensino teria total eficiência? (.) será que teria mais eficiência do que o ensino tradicional? (Entrevista) (CARANDINA, 2019 p. 120)
\end{abstract}

Os questionamentos de Eduardo (FI) sobre a eficácia do planejamento podem ser semelhantes aos questionamentos de professores que se deparam com o PBT ou com o uso de tarefas em suas aulas. De acordo com Van den Branden (2016), implementar o PBT em suas aulas é um processo gradual e de muita aprendizagem, tendo em vista que exige do professor estudo, como mencionou Eduardo (FI), dedicação e reflexão, pois é um planejamento que se mostra diferente das formas mais tradicionais de ensino. Para o autor, questionamentos como os de Eduardo (FI) são comuns, porque no PBT o professor exerce um papel que não é o de controlador das ações. Então, a imprevisibilidade pode deixar o professor mais inseguro em relação ao que será produzido pelos alunos em sala de aula e como ele irá lidar com esse fato. Diante disso, defendemos que os professores possam ter a possibilidade de cada vez mais estar em contato com o PBT, não só em contextos de extensão, mas também em seus próprios contextos de atuação. Consideramos que o contato com experiências de prática e estudo de teoria possa ajudar os professores a 
refletirem sobre diferentes tipos de ensino em sala de aula. Acreditamos, assim, que essas oportunidades possam também auxiliar na reflexão sobre esses questionamentos, como verificamos no trecho apresentado por Eduardo durante uma aula do curso sobre o estudo de teoria:

\section{Excerto 9. Eduardo}

Então eu queria acrescentar que o conteúdo teórico me ajudou bastante (.) porque eu nunca dei aula então é um pouco difícil você criar um (.) um direcionamento assim (.) é muito difícil você por em prática e criar um primeiro plano (.)(Relato durante o curso de extensão) (CARANDINA, 2019 p. 121)

Eduardo (FI) relata que o estudo de teoria o ajudou a compreender o planejamento, pois, para ele, era muito difícil pôr em prática os preceitos da teoria devido à sua inexperiência em sala de aula. Segundo KfouriKaneoya (2009), esse contato com teoria é ainda mais significativo para os professores em formação inicial, como é o caso de Eduardo, pois isso pode fazer com que eles tenham a oportunidade de refletir criticamente sobre suas crenças e pressupostos, analisando de que forma tudo isso pode ser útil para a construção de conhecimentos sobre novas teorias e práticas pedagógicas. Com esse estudo, o professor parte de uma Competência Implícita para a construção de sua abordagem de ensinar.

Diferentemente de Eduardo, para Vivian (FI), o PBT é um ensino que tende a ter maior eficácia, pois a professora demonstra acreditar no potencial do planejamento, conforme veremos a seguir:

\section{Excerto 10. Vivian}

Hum :: eu entendo que o aluno :: (.) como (.) como eu posso explicar?(.) eu acho que dá mais resultado (.) que o aluno vai tirar mais proveito daquilo e ele não vai se sentir tão (.) como eu falo? (.) tão sendo analisado mesmo (.)

(...)Eu acredito que tarefa seja aquilo que você (.) que você vai usar língua (.) vai dialogar com o seu colega (.) e também vai utilizar outros campos pra responder aquela pergunta (...) do tipo quando você fala (.)ah (.) faça um texto sobre isso (.) daí você vai usar um pouco mais a sua gramática (Entrevista) (CARANDINA, 2019 p. 121) 
Vivian (FI) define tarefa de forma semelhante aos colegas, como ao citar a necessidade de os alunos utilizarem a língua para que possam estabelecer diálogos entre si. Podemos inferir que essa compreensão da participante se refere ao uso da língua-alvo para a comunicação, assim como para mobilizar outros conhecimentos, como os gramaticais.

Podemos notar, nos relatos dos professores, uma preocupação com a gramática como um ponto persistente, que ainda chama atenção. Isso pode ocorrer, provavelmente, pela cultura de ensinar deles, bem como pela tradição do ensino de línguas calcada no ensino da forma. Isso pode levar os professores a acreditar que, no processo de aquisição da língua, o aluno necessite do ensino de gramática de maneira explícita. Para os professores em formação continuada esse é outro agravante, visto que, em muitos contextos, o ensino tradicional ainda é a única opção de ensino e, devido a isso, os professores, por não conseguirem se desvencilhar dessa situação, tendem a se apoiar no ensino da gramática, como podemos perceber na fala da professora Aline nos trechos abaixo:

\begin{abstract}
Excerto 11. Aline
eu fiquei (.) nossa gente como eu me desprendo da gramática querendo saber a diferença do will e goingto(.) não consegui encontrar uma solução pra isso (Relato durante o curso de extensão)

(...)

mas a gente/ ah eu não sei (.) eu tenho muita tendência pra fugir pra gramática (.) eu não sei (.) também pela minha aprendizagem (.) sempre (.) gramática (.) gramática (.) gramática (.) sempre quando eu fui da aula de português para estrangeiro foi muito difícil (.) é que tem que ficar na base de temáticas (.) não quer que fique na gramática (.) gente é muito difícil (.) você fala assim (.) como eu vou mostrar a diferença pra ele de : : (.) quando ele foi usar o mas e o mais (.) se eu não der as duas estruturas (.) (Relatos durante o curso de extensão) (CARANDINA, 2019 p. 122)
\end{abstract}

Segundo Van den Branden (2016), um dos motivos que fazem com que o professor modifique o PBT é justamente o fato de atribuírem a aprendizagem do aluno somente ao ensino explícito da forma. Ainda de acordo com o autor, os professores modificam as tarefas para que elas 
possam condizer com o que acreditam ser necessário para a aprendizagem do aluno, com sua abordagem e, principalmente, com as demandas do contexto em que atuam. Por isso, se temos ainda um predomínio do ensino gramatical é de se esperar que os professores privilegiem o ensino da gramática para seus alunos. Além disso, a competência implícita (ALMEIDA FILHO, 1993) dos professores também influencia as ações de um professor, tendo em vista que, provavelmente, Aline vivenciou tipos de ensino com foco na gramática.

Outro ponto que merece destaque, com relação ao contexto em que atuam os professores, são os materiais didáticos utilizados, que podem ter muita influência na maneira como se ensina, pois muitos se apoiam neles como única opção possível de insumo para o aluno. A seguir, apresentamos um trecho da participante Carla (FC), em que ela define o PBT por meio de um livro didático:

\section{Excerto 12. Carla}

Se eu fosse explicar pra alguém (...) eu não sei o que eu explicaria (.) ah (.) é porque tem um livro espanhol chamado gente (.) é um livro de língua espanhola que é feito por tarefas (.) é um livro que já tem enfoque de tarefas (.) que já diz que tem enfoque por tarefas (.) e é um livro que as atividades são muito mais sobresalintes do que os aspectos gramaticais (.) que aparece de um lado (.) digamos assim que eles quase não aparecem (.) e todas as atividades são tarefas (.) e são todas destinadas a você ter que fazer alguma coisa (...) ai vai ter várias tarefinhas (.) umas são individuais e outras são coletivas (.) então sempre que eu lembro enfoque de tarefas é por ele (.) (Entrevista) (CARANDINA, 2019 p. 123)

Podemos entender que Carla (FC) define o PBT como um ensino em que as atividades assumem maior destaque nas aulas e têm um papel mais importante. Por sobressalientes, podemos entender que a professora utiliza uma palavra em espanhol, cujo significado em português é "marcante", "notável”, "destaque", para apontar que, no livro em questão, as tarefas são predominantes e os aspectos gramaticais quase não são abordados de forma explícita. Reconhecemos que as definições da professora são um pouco vagas quando comparadas com as definições apresentadas por seus colegas de curso, talvez pelo fato de Carla (FC) 
basear sua compreensão sobre o PBT em um livro didático que ela utiliza. Muitos materiais didáticos declaram-se baseados em tarefas, mas nem sempre, de fato, o são (BARBIRATO, 2005; 2018).

Observamos, então, que os participantes compartilham de várias compreensões. Para Aline (FC), o PBT é regido por uma abordagem e tem potencial para promover interação com foco no sentido. Da mesma forma, para Gabriela, o PBT tem uma finalidade e é um ensino que visa promover a aquisição de língua por meio de um ambiente interativo. Eduardo argumenta que o PBT promove o uso da língua para comunicação em que o foco também é a interação entre os alunos, mas, para ele, é preciso que o planejamento seja mais bem estudado pelos professores, pois há ainda um questionamento quanto à sua eficácia. A interação também é um dos aspectos que mais se destaca nas falas de Jorge e Manuela, quando os professores em formação inicial são questionados a explicar como definem o planejamento. Para Manuela, apresentar uma temática que seja familiar ao aluno também é relevante para que ele se sinta mais motivado a realizar as tarefas. Vivian declara que concebe o PBT como um ensino que traz mais resultados para os alunos se comparado a um ensino mais tradicional.

\section{Considerações finais}

Iniciamos nossas considerações, primeiramente, defendendo nosso ponto de vista de que o uso do PBT na aula de línguas apresenta potencial para a construção de um processo de ensino e aprendizagem mais significativo e contextualizado para os alunos e que pode contribuir mais fortemente para que a aquisição bem-sucedida ocorra. Pensamos que as tarefas são um tipo de atividade que se alinha bem às necessidades dos alunos e vai ao encontro das características que temos buscado para nossas salas de aula. Por isso, reconhecemos a importância de os professores serem expostos a oportunidades de discussão e experiências com a elaboração e o uso delas. Para tanto, apontamos para a necessidade da formação reflexiva do professor e para que oportunidades de estudo e prática sobre o PBT possam ser criadas para os professores.

No que concerne às tarefas, alguns autores, (PRHAHBU, 1987; NUNAN, 1989; SKEHAN,1996; XAVIER,1999; ELLIS, 2003; 
BARBIRATO; 2005, RICHARS, 2006), apesar de não concordarem plenamente entre si, apresentam alguns critérios em comum, os quais a maioria reconhece como definidores de tarefa. Esses critérios que eles apontam de forma convergente são: o foco no sentido, o resultado comunicativo e o uso da língua-alvo com potencial para criar interação. Tendo isso em vista, a seguir apresentamos um quadro relacionando as concepções apresentadas pelos participantes, com essas definições em comum para alguns autores.

Quadro 1. Concepções dos professores em formação sobre tarefa

\begin{tabular}{|l|c|c|c|}
\hline \multirow{2}{*}{$\begin{array}{l}\text { Professores } \\
\text { em formação }\end{array}$} & \multicolumn{3}{|c|}{ Critérios definidores de tarefa } \\
\cline { 2 - 4 } & Foco no sentido & Interação & Resultado \\
\hline Aline & $*$ & $*$ & $\mathrm{X}$ \\
\hline Carla & $\mathrm{X}$ & $*$ & $\mathrm{X}$ \\
\hline Gabriela & $*$ & $*$ & $*$ \\
\hline Eduardo & $*$ & $*$ & $\mathrm{X}$ \\
\hline Jorge & $\mathrm{X}$ & $*$ & $\mathrm{X}$ \\
\hline Manuela & $\mathrm{X}$ & $*$ & $\mathrm{X}$ \\
\hline Vivian & $\mathrm{X}$ & $*$ & $\mathrm{X}$ \\
\hline
\end{tabular}

Fonte: CARANDINA, 2019, p. 125

Concluímos, assim, que todos os participantes mencionaram o critério criação de oportunidades de interação em suas definições do termo tarefa. Essa compreensão pode ter se originado talvez por uma ênfase que possa ter sido dada durante o curso de extensão para a natureza interativa

$2 *$ professor apresentou esse critério em seus relatos.
$X=$ professor não apresentou esse critério em seus relatos. 
das tarefas. Essa ênfase pode ter ocorrido involuntariamente nas discussões e nas leituras realizadas. Outra explicação pode estar ligada à abordagem desses participantes, que podem ter tido uma visão de língua como comunicação, voltada para a interação.

Notamos também que apenas Gabriela definiu as tarefas de acordo com os três critérios apresentados. Aline e Eduardo também apontaram o foco no sentido como sendo um dos critérios definidores. Gabriela e Aline já atuam em sala de aula e se encontravam em momentos mais avançados de sua formação no momento da coleta de dados e, por isso, podemos inferir que as professoras possuíam uma maturidade acadêmica para melhor lidar com o estudo de teorias. Contudo, Carla, que também já atuava como professora no momento da coleta e já havia finalizado a pós-graduação, não apresentou as mesmas concepções. Podemos inferir que, pelo fato de a professora não ter frequentado todas as aulas do curso, sua compreensão das tarefas pode ter sido prejudicada, pois, conforme Eduardo declarou em trecho apresentado na análise, o estudo da teoria foi de suma importância para a compreensão do planejamento e para a elaboração das tarefas. Outro dado que pode ser considerado no caso de Carla é a possibilidade de sua abordagem não condizer com os preceitos do PBT, influenciando assim sua compreensão sobre o PBT, o que resultou em concepções diferentes dos demais participantes.

No tocante à imaturidade dos professores em formação inicial, percebemos que esse pode ter sido o caso de Jorge, Vivian e Manuela, pois eles apresentaram concepções pouco fundamentadas pela teoria, diferente de Eduardo. Porém, não podemos afirmar em que medida os professores aprofundaram seus estudos sobre a teoria durante o curso, apenas no caso de Eduardo, que informou que a teoria foi de suma importância, portanto inferimos que o professor teve contato com os textos propostos.

Os resultados demonstram que o curso contribuiu muito para que os participantes compreendessem e pudessem definir o termo tarefa e até diferenciá-la de outros tipos de atividades. Por um lado, os dados revelaram que os participantes conseguiram definir o termo tarefa coerentemente com os critérios definidores apresentados por estudiosos do referente tipo de planejamento, porém os participantes apresentaram uma ênfase para o princípio da criação de oportunidades para interação. Por outro lado, o critério "apresentar um resultado comunicativo", essencial para diferenciar 
tarefa de outros tipos de atividades, foi mencionado apenas por um participante. Esse resultado pode nos levar a pensar que, provavelmente, os participantes não atentaram o suficiente para esse critério ou não tiveram tempo suficiente para amadurecer todos os critérios. Por fim, sabemos que a formação de professores é um processo e que demanda tempo e reflexão dos professores. Acreditamos, desse modo, que o curso contribuiu positivamente para a compreensão dos participantes, mas reconhecemos a necessidade de mais tempo e mais oportunidades de discussão, reflexão e utilização de tarefas na sala de aula para que a compreensão possa ser mais profunda.

\section{Referências}

ABRAHÃO, M. H. V. A formação inicial e o desenvolvimento profissional do professor de línguas estrangeiras: práticas e pesquisas. Revista Horizontes de Linguística Aplicada, Brasília, v. 5, n. 2, p. 8-23, 2006. Disponível em:

<https://periodicos.unb.br/index.php/horizontesla/article/view/28323>. Acesso em: 15 nov. 2020.

ALMEIDA FILHO, J. C. P. Dimensões comunicativas no ensino de línguas. Campinas: Pontes, 1993.

ALMEIDA FILHO, J. C. P.; BARBIRATO, R. de C. Ambientes comunicativos para aprender língua estrangeira. Trabalhos em Linguística Aplicada. Campinas, v. 36, p. 23-42, 2000. Disponível em: <https://periodicos.sbu.unicamp.br/ojs/index.php/tla/article/view/8639311> . Acesso em: 15 nov. 2020.

BARBIRATO, R. de C. Tarefas geradoras de insumo e qualidade interativa na construção do processo de aprender LE em contexto inicial adverso. 2005. 281. Tese (Doutorado em Linguística Aplicada) - Instituto de Estudos da Linguagem. Universidade Estadual de Campinas. Campinas -2005 . 
BARBIRATO, R. de C. Planejamento Baseado em Tarefas subjacente a um material didático para o ensino de línguas: conceitos e compreensões reveladas. In: BARBIRATO, R. de C.; SILVA, V. L. T. Planejamento de cursos de línguas: traçando rotas, explorando caminhos. Campinas: Pontes Editores, 2016. p. 117-142.

BARBIRATO, R. de C., CARANDINA, M. P. Elaboração de tarefas comunicativas por professores em formação inicial: concretizando princípios, criando sentidos. Revista Horizontes de Linguística Aplicada, Brasília, v. 18, n. 2, p. 139-166, 2019.

Disponível em:

$<$ https://periodicos.unb.br/index.php/horizontesla/article/view/25147>. Acesso em: 15 nov. 2020.

CARANDINA, M. P. A materialização de um planejamento temático baseado em tarefas em contexto de formação inicial de professores. (Iniciação científica - UFSCar/CNPq) - Universidade Federal de São Carlos. São Carlos, 2015.

CARANDINA, M. P. Planejamento Temático Baseado em Tarefas na formação inicial de professores de línguas. (TCC) - Universidade Federal de São Carlos. São Carlos, 2017.

CASSOLI, E. R. Aprender LE com planejamento e material comunicativos temáticos para desenvolver competência comunicativa. 2011. $236 \mathrm{f}$. Dissertação (Mestrado em Linguística) - Programa de Pós-Graduação em Linguística, Universidade Federal de São Carlos. São Carlos, 2011.

ELLIS, R. Task-based language learning and teaching Oxford: Oxford University Press, 2003.

EMÍDIO, D. E. Planejamento Temático Baseado em Tarefas no ensino e aprendizagem de inglês a distância. 2017. 318 f. Tese (Doutorado em Linguística) - Programa de Pós-Graduação em Linguística, Universidade Federal de São Carlos. São Carlos, 2017. 
Compreensões de professores acerca do termo tarefa comunicativa

KUMARAVADIVELU, B. The postmethod condition: (e)merging strategies for second/ foreign language teaching. TESOL Quarterly, v. 28, n. 1, p. 27-48, 1994.

KUMARAVADIVELU, B. Beyond methods: macrostrategies for language teaching. Yale University Press, 2003.

NUNAN, D. Designing tasks for the communicative classroom. Cambridge: CUP, 1989.

PRABHU, N. S. Second language pedagogy. Oxford: Oxford University Press, 1987.

PÉRICO, A. G. Planejamento Temático Baseado em Tarefas no ensino de inglês para crianças: percurso reflexivo e analítico de uma professora. 2018. 403f. Tese (Doutorado em Linguística) - Programa de PósGraduação em Linguística, Universidade Federal de São Carlos. São Carlos, 2018.

SKEHAN, P. A framework for the implementation of task-based instruction. Applied Linguistics, v. 17, p. 38-62,1996.

SKEHAN, P. Task-based instruction. Language Teaching, v. 36, p. 1-14, 2003.

XAVIER, Rosely Perez. A aprendizagem em um programa temático de língua estrangeira (inglês) baseado em tarefas em contextos de quinta série do ensino fundamental. 1999. 564f. Tese (doutorado) - Universidade Estadual de Campinas, Instituto de Estudos da Linguagem, Campinas,1999.

XAVIER, R. P. Language tasks and exercises: how do teachers perceive them?. In: I Congresso Internacional da Abrapui, 2007, Belo Horizonte. Novos desafios em língua e literatura. Belo Horizonte: Faculdade de Letras - UFMG, 2007. v. 1, p. 1-15. 
XAVIER, R. P. O que os professores de línguas estrangeiras necessitam saber sobre o ensino baseado em tarefas? A formação de professores de linguas: novos olhares. Campinas, v. 1, p. 147-172, 2011.

XAVIER, R. P. Revisitando o conceito de tarefas comunicativas. Caderno de Letras (UFPEL), v. 13, p. 35-46, 2007.

XAVIER, R. P Planejamento de Ensino Baseado em Tarefas. In: BARBIRATO, R. de C.; SILVA, V. L. T. Planejamento de cursos de línguas: traçando rotas, explorando caminhos. Campinas: Pontes Editores, 2016. p. 15-44.

Recebido em: 15/06/2020

Aceito em: 05/11/2020

Title: Teachers' conceptions of the term "communicative task" 